\title{
Culturing Phakopsora pachyrhizi on Detached Leaves and Urediniospore Survival at Different Temperatures and Relative Humidities
}

\author{
M. Twizeyimana, Department of Crop Sciences, University of Illinois at Urbana-Champaign; and G. L. Hartman, \\ United States Department of Agriculture-Agricultural Research Service and Department of Crop Sciences, Univer- \\ sity of Illinois, Urbana 61801
}

\begin{abstract}
Twizeyimana, M., and Hartman, G. L. 2010. Culturing Phakopsora pachyrhizi on detached leaves and urediniospore survival at different temperatures and relative humidities. Plant Dis. 94:1453-1460.

Soybean rust, caused by Phakopsora pachyrhizi, is one of the most important foliar diseases of soybean worldwide. In a series of experiments, multiple objectives were addressed to determine the (i) longevity of detached soybean leaves, (ii) reproductive capacity of uredinia on leaves inoculated and/or incubated on the abaxial versus adaxial side of the leaf, (iii) reproductive capacity of uredinia and urediniospore germination when spores were harvested at regular intervals or all at once, and (iv) effect of temperature and relative humidity (RH) on urediniospore germination. A detached-leaf assay using agar medium amended with 6-benzylaminopurine performed better in retarding leaf chlorosis than filter paper alone among five soybean genotypes. Among the three susceptible genotypes tested, detached leaves of cv. Williams 82 had the lowest level of leaf chlorosis and often allowed for the greatest urediniospore production and germination rate. Temperature and RH played significant roles in survival of urediniospore as measured by germination rates. Viable urediniospores were harvested from infected soybean leaves maintained at room temperature ( 23 to $24^{\circ} \mathrm{C}$ at 55 to $60 \% \mathrm{RH}$ ) for up to 18 days, whereas freshly harvested urediniospores that were desiccated for $12 \mathrm{~h}$ before being placed in vials and maintained at room temperature remained viable for up to 30 days. Urediniospore hydration was the major factor for the dormancy reversion; thermal shock with hydration and no thermal shock with hydration treatments had consistently similar urediniospore germination rates. In the RH experiment, urediniospores harvested from inoculated leaf pieces maintained at $85 \% \mathrm{RH}$ had the highest germination rates compared with higher and lower RH. Improvement in $P$. pachyrhizi cultural techniques and understanding of urediniospore survival will enhance our knowledge of the pathogen biology, host-plant relationship, and conditions that favor the infection, reproduction, and survival of the pathogen.
\end{abstract}

Soybean rust, caused by Phakopsora pachyrhizi Syd. \& P. Syd., is a major disease that limits soybean (Glycine max (L.) Merr.) production in many areas of the world. P. pachyrhizi was first reported in Japan in 1902 (17) and, for many decades after 1902, it was limited to the Eastern Hemisphere (9). Soybean rust was reported from the major soybean-producing areas in Africa between the late 1990s and early $2000(2,25,31)$, Paraguay in 2001, Brazil in 2002 (59), and Argentina in 2003 (42).

Corresponding author: G. L. Hartman

E-mail: ghartman@illinois.edu

Trade and manufacturers' names are necessary to report factually on available data; however, the USDA neither guarantees nor warrants the standard of the product, and the use of the name by USDA implies no approval of the product to the exclusion of others that may also be suitable.

Accepted for publication 16 August 2010.

doi:10.1094/PDIS-02-10-0131

This article is in the public domain and not copyrightable. It may be freely reprinted with customary crediting of the source. The American Phytopathological Society, 2010.
P. pachyrhizi was first reported from the continental Unites States in 2004 in Louisiana (45), and has become established in the southern United States along the Gulf of Mexico, overwintering on kudzu (38). The overwintering of $P$. pachyrhizi on hosts such as kudzu and the potential longdistance transport of urediniospores (23) provide sources of inoculum for epidemics to develop in soybean each year. Although yield losses in the United States have not been extensive, losses of up to $80 \%$ have been reported from experimental plots in Taiwan (16) and up to 55\% from experiments conducted in Southern Africa, South America, and the United States $(34,35)$.

Like other rust fungi, $P$. pachyrhizi is an obligate parasite and requires living host tissue to establish and cause infection. This renders the in vitro manipulation (e.g. growing the pathogen on culture media) difficult (13). Axenic culture of a limited number of rust fungi, including Cronartium fusiforme (19), Peridermium pini (40), and Puccinia spp. (30), has been successful. Attempts to culture Phakopsora pachyrhizi have not been successful (58).

In vivo culturing of $P$. pachyrhizi on detached soybean leaves placed on agar- amended media $(10,39,53)$ or on filter paper (38) inside petri dishes has been successful for maintaining leaf pieces to evaluate the host-pathogen interactions $(10,39,54)$. Detached-leaf culturing has also been useful to study host-pathogen interactions for other rust fungi such as Puccinia coronata (24), Uromyces viciaefabae (18), P. sorghi (21), and non-rust pathogens Mycosphaerella fijiensis (55) and Phytophthora infestans (49). Some advantages of detached-leaf resistance evaluation assays compared with wholeplant assays include improved environmental and pathogen control (41). The use of a detached-leaf assay to evaluate soybean rust resistance was validated in a Nigerian study (53) that demonstrated that the disease severity recorded in the detached-leaf evaluations was positively correlated with that observed on entire plants in the greenhouse or field.

Urediniospores of Phakopsora pachyrhizi have a relatively short life compared with spores of other fungi because of their thin spore wall (29). It was reported that urediniospores freshly harvested from infected leaves, then placed inside tightly sealed plastic microtubes and maintained at room temperature $\left(25 \pm 3^{\circ} \mathrm{C}\right)$, survived for up to 18 days (13).

Methods for short- and long-term fungal preservation have been reported $(13,36,48)$. Short-term maintenance of soybean rust urediniospores is done with periodic transfer of the pathogen to fresh detached leaves. The most suitable long-term storage for rust urediniospores has been in liquid nitrogen (12). Frozen urediniospores are revived by heat-shock followed by hydration treatments $(8,13)$.

Temperature, humidity, solar radiation, and other factors affect fungal survival and the infection process $(1,11,14)$. Most fungal spores are extremely sensitive to short periods (i.e., hours) of intense sunlight $(32,43)$. Like other fungi, the viability of $P$. pachyrhizi urediniospores at the field level or in the atmosphere can be greatly affected by temperature and relative humidity $(\mathrm{RH})$. An optimal temperature range of 15 to $26^{\circ} \mathrm{C}$ has previously been reported for urediniospore germination (50), with germination rates decreasing following the exposure of urediniospores to temperatures of 28.5 to $42.5^{\circ} \mathrm{C}(28)$. Also, work on the longevity of P. pachyrhizi urediniospores during periods of solar radiation has been done (22). 
A key requirement to successfully prevent yield losses due to soybean rust is to understand more about the biology of $P$. pachyrhizi, the host-pathogen relationship, and the epidemiology of the disease. Many studies have contributed to our knowledge of the infection process $(26,27)$, the host range $(37,46)$, and conditions that favor the infection, development, and dissemination of the pathogen $(7,22,38)$.

With the aim to improve methods of $P$. pachyrhizi isolation, preservation, urediniospore increase, and techniques for inoculation, and to increase understanding of the conditions that favor disease development, multiple objectives were addressed to determine: (i) longevity of detached soybean leaves, (ii) reproductive capacity of uredinia when leaves were inoculated and/or incubated using the abaxial versus adaxial side, (iii) reproductive capacity of uredinia and urediniospore germination when harvested at regular intervals or all at once, and (iv) effect of temperature and $\mathrm{RH}$ on urediniospore germination.

\section{MATERIALS AND METHODS}

Plant material and propagation. The susceptible soybean genotypes cv. Williams 82, TGx 1485-1D (a breeding line from Nigeria), and cv. Taki Hime (Japan), with no known soybean rust resistance genes, and resistant genotypes Plant Introduction (PI) 462312 (Rpp3) and PI 459025B (Rpp4) were used.

Seed were sown in $12-\mathrm{cm}$-diameter pots (two plants per pot) in a soil-less mix (Sunshine Mix, LC1; Sun Gro Horticulture Inc., Bellevue, WA), fertilized at planting with slow-release pellets (Osmocote 19-6$12 ; 1$ to 2 pellets $/ \mathrm{cm}^{2}$ ), and placed inside a growth chamber (Percival Scientific, Inc., Boone, IA) maintained at 20 to $24^{\circ} \mathrm{C}$ and 60 to $70 \% \mathrm{RH}$ with $12 \mathrm{~h}$ of light (500 $\mu \mathrm{mol} \mathrm{m} \mathrm{m}^{-2} \mathrm{~s}^{-1}$ PAR). Leaves were harvested from plants at growth stage V2 to V3 (approximately 28 to 40 days old) and washed in three to four changes of sterile distilled water before inoculation.

Inoculum preparation and inoculation. One monospore isolate, FL07-1, originally collected from infected soybean leaves from Gadsden County, FL in 2007, was used for all experiments. The singlespore isolation of FL07-1 was conducted as follows. Urediniospores ( 0.5 to $2 \mathrm{mg}$ ) harvested from infected leaf samples were used to inoculate the abaxial surface of Williams 82 leaf pieces. A spore suspension of $100 \mu \mathrm{l}\left(1 \times 10^{3}\right.$ spores $/ \mathrm{ml}$ of water $)$ was sprayed on each leaf piece using an atomizer attached to an air compressor (53). A single inoculated leaf piece (approximately 4 by $4 \mathrm{~cm}$ ) was carefully placed in a 9-cm-diameter plastic petri dish with adaxial side appressed on $1 \%$ water agar (WA) amended with 6-benzylaminopurine (BAP) at $2 \mathrm{mg} / \mathrm{liter}$. Petri dishes containing leaf pieces were incubated in the dark for a period of $12 \mathrm{~h}$ fol- lowed by a cycle of 14 and $10 \mathrm{~h}$ light (380 umol $\mathrm{m}^{-2} \mathrm{~s}^{-1}$ ) and darkness, respectively, inside a tissue chamber (Percival Scientific, Inc.) maintained at $23^{\circ} \mathrm{C}$. Prior to incubation, dishes were placed inside zip bags (Webster Industries, Peabody, MA). When uredinia erupted (9 to 13 days after inoculation), urediniospores (10 to 30 ) from a single uredinium were picked using a sharp sterile needle under a dissecting microscope at $\times 20$ magnification and were mixed with $40 \mu \mathrm{l}$ of sterile water. The urediniospore suspension was then spread onto $1.5 \%$ WA medium with a sterile glass rod. Two hours later, a single germinated urediniospore was removed using a sharp sterile needle and transferred to a drop of sterile water with $0.01 \%$ Tween 20 and placed on a new detached leaf of Williams 82 appressed on $1 \%$ WA amended with BAP in a petri dish. A different sharp sterile needle was used for picking a new germinating urediniospore. All urediniospores resulting from a single uredinium that developed from the single spore were harvested and multiplied for use as inoculum based on the detached-leaf assay (53).

Effect of two maintenance substrates on longevity of detached leaves. Experiment 1 was arranged as a split plot in a randomized complete block design with three replications. The main plots were the substrate treatments and the subplots were the soybean genotypes (Williams 82, TGx 1485-1D, Taki Hime, PI 462312, and PI 459025B). Two substrates, one consisting of $1 \%$ WA medium amended with BAP $(2$ $\mathrm{mg} / \mathrm{liter}$ ) and the other consisting of 90mm-diameter filter papers (Whatman International Ltd., England), were tested to maintain detached leaves of the five soybean genotypes. Leaflets were excised from plants, washed in three changes of sterile distilled water, and cut into approximately 4-by-4-cm pieces to fit into 9cm-diameter petri dishes. Sterile filter papers (two per dish) were saturated with sterile distilled water (approximately 3.5 $\mathrm{ml} /$ dish) prior to placing leaf pieces in dishes. Additional water $(2 \mathrm{ml} / \mathrm{dish})$ was added at 10-day intervals to keep the filter papers saturated. Petri dishes with leaf pieces on $1 \%$ WA medium amended with BAP or saturated filter paper substrates were incubated as described. Detached leaves were rated visually for chlorosis using a 1-to-9 scale, in which $1=0$ to $5 \%$ chlorosis (i.e., 95 to $100 \%$ green color), 2 $=5$ to $20,3=20$ to $30,4=30$ to $40,5=$ 40 to $50,6=50$ to $60,7=60$ to $70,8=70$ to 80 , and $9=>80 \%$ chlorosis (53).

Effect of abaxial versus adaxial leaf inoculation on urediniospore reproduction. Experiment 2 consisted of a threelevel-factorial combination with substrate (BAP and filter paper), genotype (Williams 82, TGx 1485-1D, Taki Hime, and PI 462312), and inoculation side (abaxial and adaxial) equaling 16 treatments arranged in randomized complete blocks with three replications. Leaf pieces collected as previously described were uniformly sprayed with $200 \mu$ lof a $1 \times 10^{4}$ urediniospore $/ \mathrm{ml}$ suspension using an air brush paint sprayer (Paasche Airbrush Co., Taiwan) attached to an air compressor. Inoculated leaf pieces placed on $1 \%$ WA medium amended with BAP in petri dishes were incubated as described. Three days after inoculation, leaf pieces were observed daily under a dissecting microscope at $\times 20$ magnification to record days to lesion appearance, days to uredinia formation and uredinia eruption, number of uredinia on the abaxial and adaxial side of leaf pieces, and uredinia per lesion. Uredinia produced on the abaxial side were counted from a 1$\mathrm{cm}^{2}$ leaf area whereas uredinia produced on the adaxial side were counted from the whole leaf piece because the numbers were so few.

Effect of harvest intervals on uredinia spore production and urediniospore germination. Experiments 3 to 5 each used leaf pieces from three genotypes (Williams 82, Taki Hime, and PI 462312). Detached leaf pieces spray inoculated with $100 \mu \mathrm{l}$ of a spore suspension (100 urediniospores $/ \mathrm{ml}$ ) on the abaxial surface of each leaf piece were incubated as previously described and arranged in a randomized complete block design with five replications. Samples of urediniospores developing on the leaf pieces were harvested periodically for spore enumeration and to record germination rates. Urediniospores were collected from a single isolated uredinium (i.e., without any uredinia close by) 1 day after uredinial eruption by dispensing $40 \mu \mathrm{l}$ of sterile distilled water with $0.01 \%$ Tween 20 using a pipette on the uredinium and aspirating the spore suspension. The spore suspension was then dispensed onto $1.5 \%$ WA in petri dishes in four places (about $10 \mu \mathrm{l}$ each). Under a dissecting microscope at $\times 20$ magnification, the total number of urediniospores (i.e., from four drops) was determined and the germination percentage was determined after $3 \mathrm{~h}$. For experiment 3, single sporulating uredinia were randomly chosen from each plate on the first day of urediniospore harvesting (one uredinium per leaf piece) and urediniospores were harvested from the same uredinium daily until production ceased. Experiment 4 was conducted like experiment 3 except that urediniospores were harvested from the same uredinium every 2 days until production ceased. For experiment 5, urediniospores were randomly collected every 2 days from different uredinia (one uredinium per leaflet) until 13 days after the initial sample was taken.

Effect of heat treatments on urediniospore survival. Experiment 6 used detached leaf pieces of Williams 82 that were inoculated as previously described and then placed on BAP-amended WA. Two days after uredinial eruption (11 to 13 days 
after inoculation), leaf sections containing a minimum of four erupted sporulating uredinia were placed in 6.4-by-10.8-cm coin envelopes (one leaflet piece per envelope) and then dried at $25^{\circ} \mathrm{C}$ (30 to $32 \%$ $\mathrm{RH}), 30^{\circ} \mathrm{C}$ (22 to $\left.25 \% \mathrm{RH}\right), 40^{\circ} \mathrm{C}$, and $50^{\circ} \mathrm{C}$ (approximately 15 and $10 \% \mathrm{RH}$, respectively) in an incubator (Isotemp Incubator; Fisher Scientific Inc,. PA). Four envelopes were removed from each temperature after $0.25,0.5,1,2,4,6,8,12$, $15,18,21$, and $24 \mathrm{~h}$. Immediately after removal from the temperature treatments, urediniospores were harvested as previously described from randomly chosen uredinia and the suspension was placed onto $1.5 \%$ WA in petri dishes in four places (10 $\mu \mathrm{l}$ each). The percent germination was determined as previously described in experiments 3,4 , and 5 .

Effect of liquid nitrogen or roomtemperature storage on urediniospore survival. Experiment 7 was a factorial experiment with two types of inoculum (freshly harvested urediniospores from infected leaflets of Williams 82 or urediniospores remaining in uredinia on infected leaf pieces) and four inoculum retrieval treatments (overnight hydration of stored urediniospores with and without a heat shock treatment of $5 \mathrm{~min}$ at $40^{\circ} \mathrm{C}$ [immediately after removal from liquid $\mathrm{N}$ ] and no overnight hydration with and without heat shock) as factors, with three replications. The overnight hydration consisted of overnight placement of uncovered cryogenic vials containing spores on filter paper saturated with distilled water in a petri dish placed in darkness at room temperature. Cryogenic vials of $1.8 \mathrm{ml}$ containing urediniospores ( 0.5 to $2 \mathrm{mg} / \mathrm{vial}$ ) or infected leaf tissues (three pieces per vial) were stored in liquid nitrogen and, every 2 months, eight vials with spores and eight vials with infected leaf tissues were retrieved from storage and percent germination on WA was recorded. The experiment lasted for a period of 8 months. Prior to the germination test, half the vials with urediniospores or infected leaf tissue were subjected to heat shock treatment $(5 \mathrm{~min}$ at $40^{\circ} \mathrm{C}$ ); this was followed by the overnight hydration (described earlier) for half of the vials with or without heat-shock treatments. Germination tests with three replicates for each treatment were conducted every 2 months following initial storage.

The procedure for experiment 8 was similar to that for experiment 7 except that urediniospores were stored in the dark at room temperature (approximately $23^{\circ} \mathrm{C}$, with 55 to $60 \% \mathrm{RH}$ ) in a laboratory instead of in liquid $\mathrm{N}$, and half of the harvested urediniospore samples were desiccated over silica gel for $12 \mathrm{~h}$ prior to being placed in storage. Samples of urediniospores were removed from storage every 4 days and tested until germination; sampling continued until the germination rate was zero.
Effect of RH on urediniospore germination. Experiment 9 used five saturated salt-solution treatments that were approximated to $92.5 \%\left(\mathrm{KNO}_{3}\right), 85 \%(\mathrm{KCl})$, $75 \%(\mathrm{NaCl}), 64 \%\left(\mathrm{NaNO}_{2}\right)$, and $47.5 \%$ $\left(\mathrm{KNO}_{2}\right) \quad \mathrm{RH}$ inside closed containers $(20,56)$. These were prepared by adding 20 $\mathrm{ml}$ of saturated salt solution into $50-\mathrm{ml}$ centrifuge tubes (Corning Inc., NY). Five tubes were included for each $\mathrm{RH}$ treatment; one tube housed a temperature/RH sensor (model TH801; Dickson Co., Addison, IL) to monitor the RH. Grids of approximately $4 \mathrm{~cm}^{2}$ were cut from aluminum mesh $\left(1.5 \mathrm{~mm}^{2}\right)$ (New York Wire, Mount Wolf, PA) and inserted into the tubes $2 \mathrm{~cm}$ above the saturated salt solution. All the tubes were maintained at room temperature (approximately $23^{\circ} \mathrm{C}$ ). Two weeks after the RH over the saturated salt solutions attained equilibrium (i.e., when vapor pressures developed in the closed environment above saturated salt solutions reached equilibrium with the saturated solutions after a certain period at a con- stant temperature; 56), soybean leaf pieces with erupted uredinia were placed on top of each aluminum grid in each tube, except for the tubes that were used to monitor the RH levels. For each saturated salt-solution treatment, samples of infected leaf pieces were removed from four tubes after 2,6 , $10,14,18,22,26$, and 30 days. Urediniospore harvest and germination tests were completed as previously described.

Data analysis. All experiments were repeated one time and data were tested for homogeneity of error variance before pooling. Pooled data were tested by analysis of variance in PROC GLM of SAS (version 9.1.3; SAS Institute Inc., Cary, NC). Data from all experiments, except experiment 2 , were analyzed using repeated measures with the PROC GLM, and curves were fitted to a nonlinear form of the logistic model using SigmaPlot (version 11; Systat Software Inc. San Jose, CA). Data on days to lesion appearance, days to uredinia formation and uredinia eruption, number of erupted uredinia on abaxial and adaxial
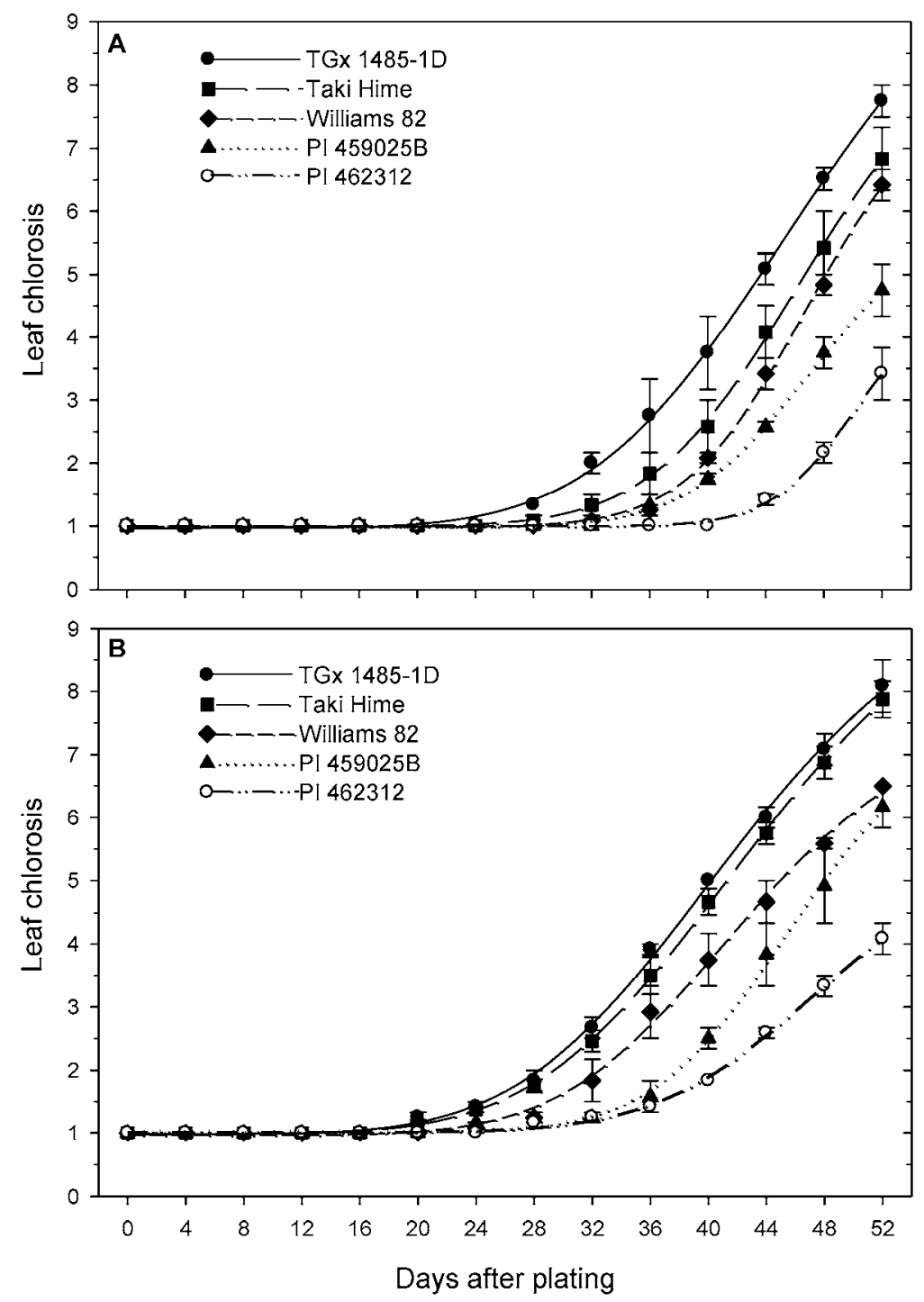

Fig. 1. Effect of agar medium amended with A, 6-benzylaminopurine and $\mathbf{B}$, filter paper on leaf chlorosis of five soybean genotypes. Vertical bars represent standard errors of the mean. 
side of leaf sections, and uredinia per lesion were analyzed using PROC GLM and means were separated using Fisher's protected least significant difference (LSD) at $\alpha=0.05$. The paired $t$ test procedure of SAS was used to compare detached leaves maintained on agar-amended medium and detached leaves on filter paper, and inoculations on the abaxial and adaxial side of the leaves. Data recorded on the spore production in experiments 3,4 , and 5 were analyzed using PROC GLM and means were separated using Fisher's protected LSD at $\alpha=0.05$.

\section{RESULTS}

Effect of two maintenance substrates on longevity of detached leaves. Differences in leaf chlorosis ratings were observed in the main plot, subplot, and interaction, indicating that rate of leaf chlorosis over time was dependent on soybean genotype and whether leaf pieces were kept on BAP-amended WA or plain, moist filter paper disks. The paired $t$ test revealed significant $(P<0.001)$ differences in leaf chlorosis between placing detached leaves on agar-amended medium and filter paper. The first observed leaf chlorosis occurred on TGx 1485-1D 20 days after plating on filter paper and 24 days after plating on BAP-amended WA. Leaf chlorosis significantly $(P<0.001)$ differed by genotype, with leaflets of TGx 1485-1D having the highest chlorosis ratings and Williams 82 the lowest ratings among the three susceptible genotypes. PI 462312 had the lowest chlorosis ratings regardless of substrate compared with the other genotypes (Fig. 1).

Effect of abaxial versus adaxial inoculation on urediniospore reproduction. The interaction between substrate (BAP and filter paper), genotype, and inoculation side (abaxial and adaxial) was not significant, nor were any of the two-way interactions, except for the interaction between genotype and inoculation side for the number of days to first lesion appearance, uredinia formation, and uredinia eruption, number of uredinia produced at abaxial side of the leaf, and number of uredinia per lesion. The interaction was due to PI 462312 having approximately two more days to first lesion appearance, uredinia formation, and uredinia eruption compared with Taki Hime, TGx 1485-1D, and Wil- liams 82. Also, regardless of substrate and inoculation side, PI 462312 had generally fewer uredinia on the abaxial side and fewer uredinia per lesion than the other genotypes (Table 1). There were also differences in genotype for the number of uredinia on the adaxial side of the leaf. Regardless of genotype and substrate, the paired $t$ test revealed significant $(P<$
$0.001)$ differences for the number of uredinia on the adaxial side between inoculations of the abaxial and adaxial side of the leaf (Table 1).

Effect of harvest intervals on uredinia spore production and urediniospore germination. Production of urediniospores harvested daily from the same uredinium decreased over time after the second har-
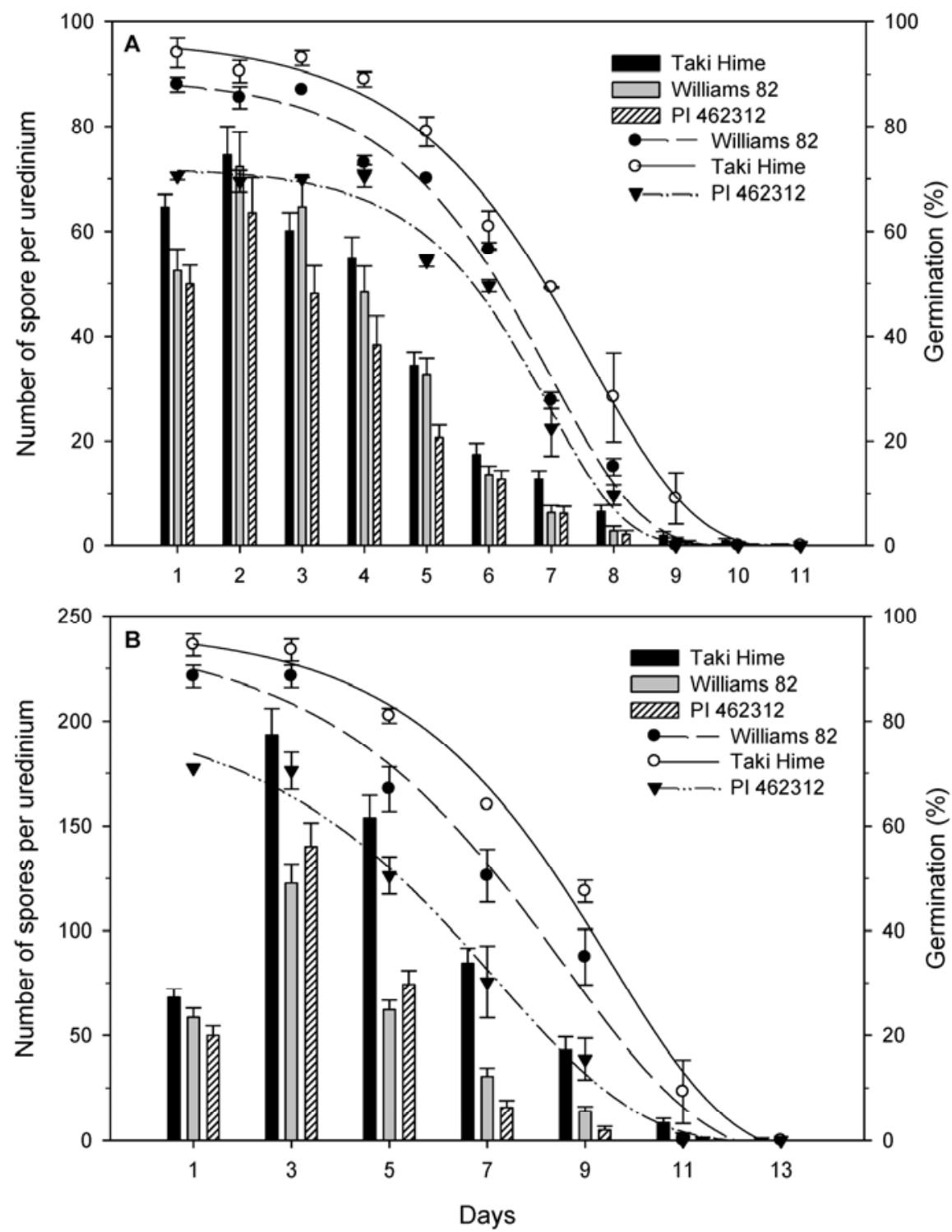

Fig. 2. Production and germination rates of Phakopsora pachyrhizi urediniospores on three soybean genotypes harvested from the same uredinium $\mathbf{A}$, daily and $\mathbf{B}$, every 2 days. Vertical bars represent standard errors of the mean.

Table 1. Means of infection data recorded from detached soybean leaflets on four genotypes inoculated with Phakopsora pachyrhizi on the abaxial or adaxial side and maintained on agar medium amended with 6-benzylaminopurine or filter paper in plastic dishes

\begin{tabular}{|c|c|c|c|c|c|c|c|}
\hline \multirow[b]{2}{*}{ Genotype } & \multicolumn{3}{|c|}{ Number of days to ${ }^{x}$} & \multicolumn{2}{|c|}{ Number of uredinia $^{y}$} & \multicolumn{2}{|c|}{ Uredinia at adaxial side ${ }^{\mathrm{z}}$} \\
\hline & $\begin{array}{c}\text { Lesion } \\
\text { appearance }\end{array}$ & $\begin{array}{c}\text { Uredinia } \\
\text { formation }\end{array}$ & $\begin{array}{l}\text { Uredinia } \\
\text { eruption }\end{array}$ & $\begin{array}{c}\text { At } \\
\text { abaxial side }\end{array}$ & $\begin{array}{c}\text { Per } \\
\text { lesion }\end{array}$ & $\begin{array}{c}\text { Abaxial side } \\
\text { inoculated }\end{array}$ & $\begin{array}{c}\text { Adaxial side } \\
\text { inoculated }\end{array}$ \\
\hline Taki Hime & $5.4 \mathrm{a}$ & $7.8 \mathrm{a}$ & $9.8 \mathrm{a}$ & $30 \mathrm{~b}$ & $2.8 \mathrm{~b}$ & $0.3 \mathrm{ab}$ & $3.1 \mathrm{~d}$ \\
\hline PI 462312 & $7.2 \mathrm{~b}$ & $10.5 \mathrm{~b}$ & $12.7 \mathrm{~b}$ & $8 \mathrm{a}$ & $0.9 \mathrm{a}$ & $0.0 \mathrm{a}$ & $0.0 \mathrm{a}$ \\
\hline TGx 1485-1D & $5.4 \mathrm{a}$ & $7.7 \mathrm{a}$ & $9.7 \mathrm{a}$ & $28 \mathrm{~b}$ & $2.8 \mathrm{~b}$ & $0.8 \mathrm{~b}$ & $2.5 \mathrm{c}$ \\
\hline Williams 82 & $5.7 \mathrm{a}$ & $7.9 \mathrm{a}$ & $9.9 \mathrm{a}$ & $26 \mathrm{~b}$ & $2.6 \mathrm{~b}$ & $0.1 \mathrm{a}$ & $2.1 \mathrm{c}$ \\
\hline
\end{tabular}

${ }^{\mathrm{x}}$ Means followed by the same letter within columns are not significantly different $(P<0.05)$.

${ }^{y}$ Uredinia at abaxial side were counted from $1 \mathrm{~cm}^{2}$ of leaflet tissue. Means followed by the same letter within columns are not significantly different $(P<0.05)$.

${ }^{\mathrm{z}}$ Uredinia at adaxial side were counted from the whole leaflet. Means followed by the same letter within both columns are not significantly different $(P<0.05)$ 
vest for all three genotypes until 10 days after the first harvest of urediniospores (Fig. 2A). For most of the sampling days, urediniospores were more abundantly produced on Taki Hime than on the other two genotypes. Urediniospore germination decreased over time and, for most sampling dates, germination rates were greatest for urediniospores harvested from Taki Hime and least for PI 562312. For instance, Taki Hime had an initial spore germination of $94 \%$ and decreased to 61 and $9 \%$ germination rates 6 and 9 days, respectively, after the first collection whereas PI 462312 had an initial spore germination of $70 \%$ and decreased to 50 and $0 \%$ germination rates after 6 and 9 days, respectively (Fig. 2A).

When urediniospores were harvested every 2 days from the same uredinium, production decreased over time after the second harvest for all three genotypes until 11 days after the initial harvest. Approximately 193 and 140 urediniospores were harvested on the second harvest (i.e., 2 days after the initial harvest) from uredinia on Taki Hime and PI 462312, respectively. By 9 days after the initial harvest for the same genotypes, spore production was reduced to approximately 43 and 5 urediniospores (Fig. 2B). Also, urediniospore germination decreased over time and, from most of the sampling days, germination rates were greatest for urediniospores harvested from Taki Hime and least for PI 462312. Approximately 91 and $9 \%$ germination rates were recorded 5 and 11 days, respectively, after the first harvest on Taki Hime and were higher than that of PI 462312, with approximately 50 and $0 \%$ germination rates for the 5 and 11 day samples, respectively (Fig. 2B).

When urediniospores were harvested from different uredinia every 2 days, production increased through time, with a slight drop in production by the last sampling day (day 13) for all three genotypes (Fig. 3). Urediniospore production was significantly greater $(P<0.001)$ for Taki Hime than PI 462312 for all but one sampling day. There was a slow decrease in germination rates over time. For example, Williams 82 and Taki Hime had initial germination rates of approximately $90 \%$ and dropped to 78 and $80 \%$, respectively, after 13 days. Urediniospores from PI 462312 had lower germination rates, with an initial rate of $74 \%$ dropping to $68 \%$ after 13 days. The germination rates were 73 and $74 \%$ for Williams 82 and Taki Hime, respectively, and 65\% for PI 462312 after 30 days.

Effect of heat treatments on urediniospore germination. Differences in percent spore germination over time were recorded, with most treatments approaching $0 \%$ germination before $8 \mathrm{~h}$ of exposure (Fig. 4). For some treatments such as 40 and $50^{\circ} \mathrm{C}, 4 \mathrm{~h}$ of exposure caused $0 \%$ germination. Uredinio- spores exposed to $25^{\circ} \mathrm{C}$ had some germination for up to $15 \mathrm{~h}$.

Effect of storage treatments on urediniospore germination. After storage in liquid $\mathrm{N}$, urediniospores that were heat shocked and those that were not heat shocked but hydrated had greater $(P<0.05)$ percent germination over time than urediniospores that were heat shocked and those that were not heat shocked without hydration (Fig. 5). With an initial germination percentage of approximately $85 \%$ for all four treatments, two treatments (heat shock with hydration and no heat shock with hydration) had greater germination percentage (approximately $73 \%$ for both treatments) after 8 months whereas the lowest percent germination was for no heat shock without hydration $(30 \%)$. Urediniospores harvested from leaf disks placed in 1.8-ml cryogenic vials and stored in liquid $\mathrm{N}$ did not germinate, even after only a day of storage in liquid $\mathrm{N}$, regardless of the treatment.

Percent germination of urediniospores stored at room temperature was greater than that of urediniospores harvested directly from infected soybean leaves maintained at room temperature. Desiccated urediniospores had lower percent germination at the beginning of the ex-

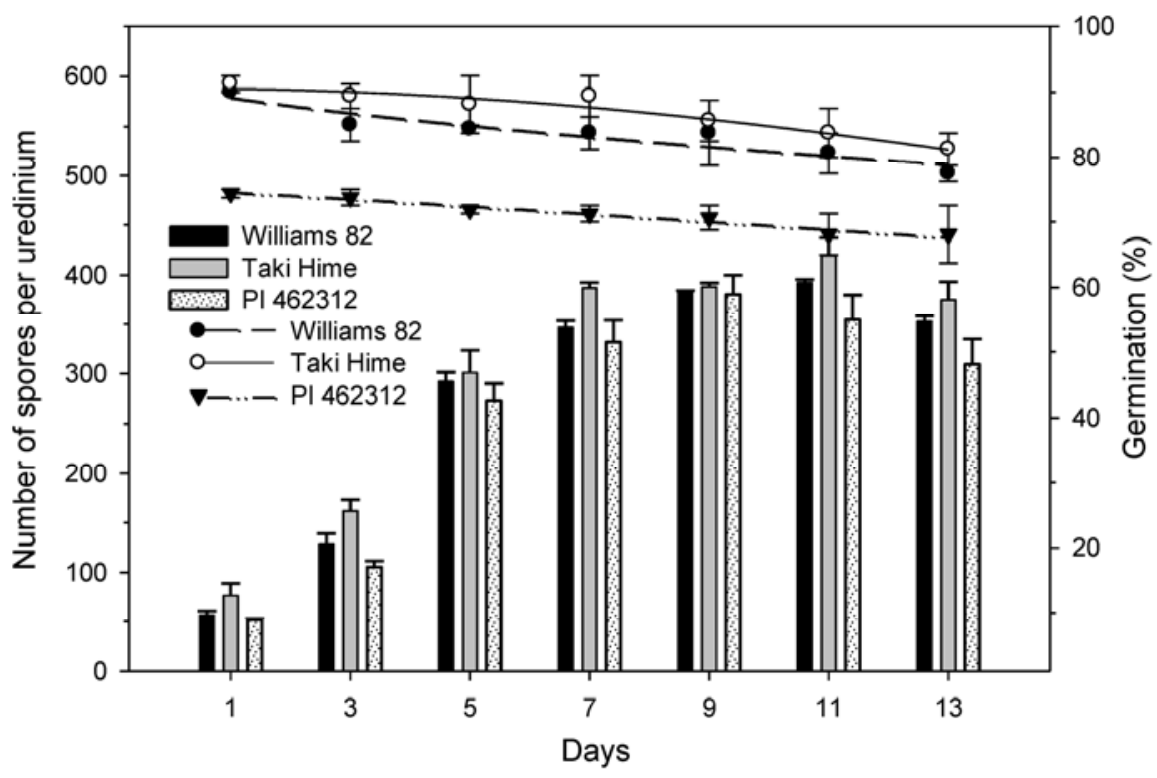

Fig. 3. Production and germination rates of Phakopsora pachyrhizi urediniospores on three soybean genotypes harvested from different uredinia every 2 days. Vertical bars represent standard errors of the mean.

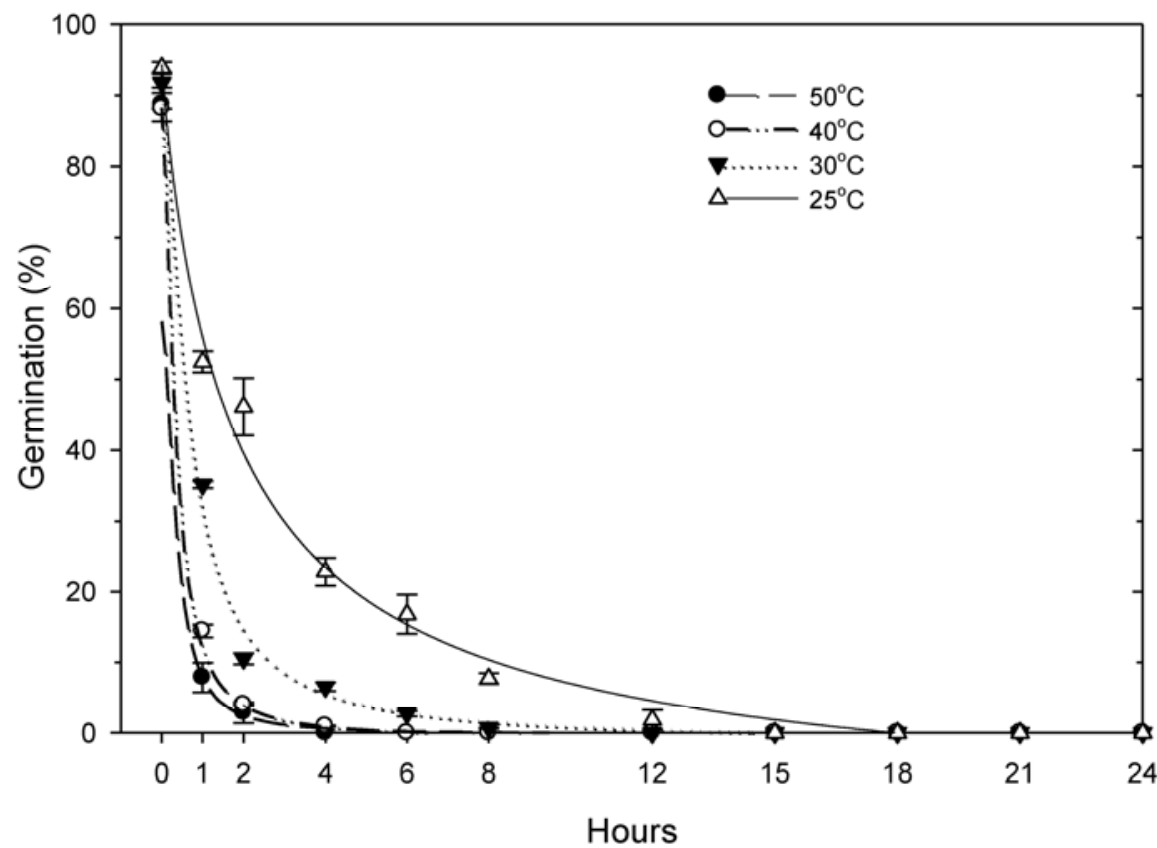

Fig. 4. Germination rates of Phakopsora pachyrhizi urediniospores exposed to four different temperatures. Vertical bars represent standard errors of the mean. 
periment compared with other treatments but had the longest survival period (30 days) (Fig. 6).

Effect of urediniospore exposure at various RHs on germination. There were significant differences $(P<0.01)$ for urediniospore percent germination of spores stored under different RHs (Fig. 7). Those exposed to $85 \% \mathrm{RH}$ had the highest germination rates over time, with some germination occurring even after 26 days. Urediniospores exposed to $75 \% \mathrm{RH}$ had the second highest germination rates over time, with some germination occurring out to 22 days. Urediniospores exposed to
92.5\% RH initially had high germination rates but rates decreased rapidly after 10 days and there was no germination after 22 days. Urediniospores exposed to the lowest RHs had generally the lowest germination rates.

\section{DISCUSSION}

Managing soybean rust requires understanding pathogen biology, host-pathogen interactions, and the conditions that favor the establishment and development of the pathogen. Like many other obligate pathogens, working with $P$. pachyrhizi requires special attention to maintaining isolates

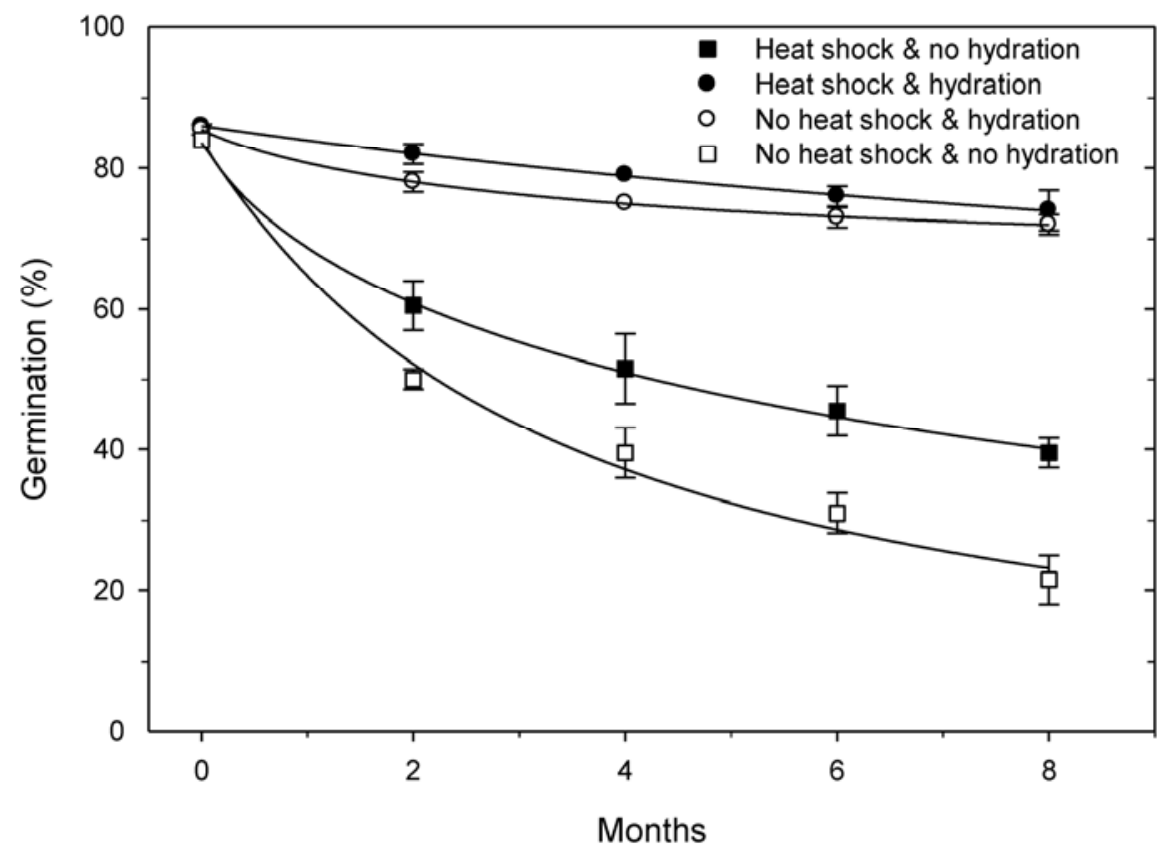

Fig. 5. Germination rates of Phakopsora pachyrhizi urediniospores stored in liquid nitrogen. Vertical bars represent standard errors of the mean.

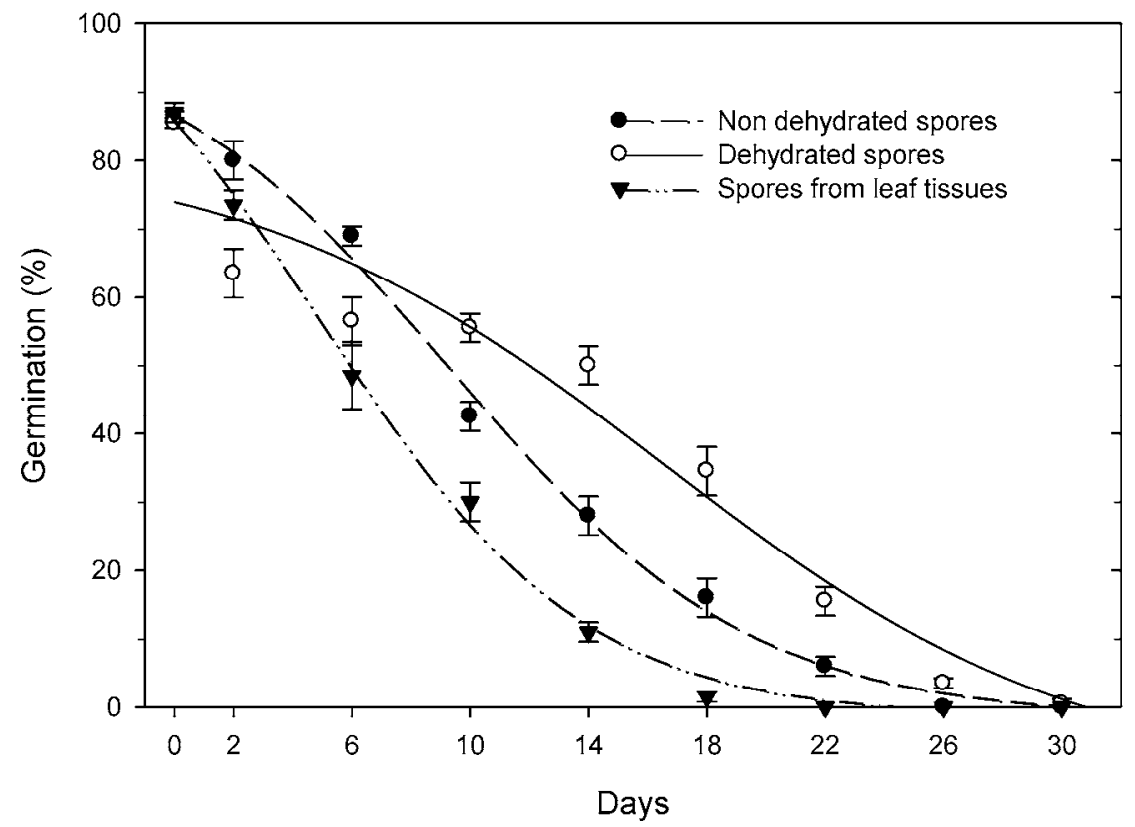

Fig. 6. Germination rates of Phakopsora pachyrhizi urediniospores stored at room temperature. Vertical bars represent standard errors of the mean. through either detached-leaf culturing or long-term storage.

The detached-leaf assay which has been used in culturing rust pathogens $(3,4,10,53)$ and other pathogens $(55,57)$ provides a method that overcomes the time and space limitations of greenhouse and field evaluations of genotypes for disease resistance. Moreover, inoculations on detached leaves were shown to be reliable with strong correlations observed between detached-leaf, greenhouse, and field disease data (53).

A critical aspect in using the detachedleaf assay is to maintain healthy leaf tissue for the period that is required for disease development and fungal reproduction (i.e., from inoculation to sporulation for $P$. pachyrhizi). However, longer periods of healthy leaf tissue are important for shortterm use of rust isolates. The detached-leaf assay using agar medium amended with BAP performed better in retarding leaf chlorosis than the filter paper method (38).

The detached-leaf assay, like the entire plant in the greenhouse or field evaluations, was sensitive to the genetic background of the host that influenced the development and multiplication of the pathogen (i.e., latent period, infection type, lesion development, and spore production in detached-leaf evaluations; 3,53). In our study, the number of days to lesion appearance was fewer and uredinia formation and uredinia eruption less on highly susceptible cultivars than on PI 462312. Also, the number of uredinia per square centimeter of leaflet tissue and spores per uredinia produced daily or every 2 days was greater on the three susceptible cultivars than on PI 462312. Similar cultivar effects on the disease parameters in detached-leaf assays have been reported $(39,53)$. The quality of spores produced may also be affected by the host cultivars $(3,53)$. In our case, the spores harvested from uredinia 1 day after eruption on PI 462312 had less germination $(75 \%)$ than spores harvested 1 day after eruption on Williams 82 or Taki Hime (90\% germination).

Typically, with soybean rust and other rust pathogens-for example, Cerotelium fici (15), Coleosporium tussilaginis (52), and Chrysomyxa rhododendri (44)uredinia form predominantly on the abaxial side of the leaf. Results from our study demonstrated that there was no difference in inoculating either side of the leaf; however, nearly all uredinia developed on the abaxial side even though lesions were observed on both sides.

Temperature, humidity, solar irradiation, and other factors can affect spore survival in the atmosphere $(5,14)$. Most spores are extremely sensitive to even a few hours of intense sunlight (32). In our study, urediniospore survival was greatly affected by temperature and RH. For instance, urediniospores were killed after 4 to $6 \mathrm{~h}$ of exposure of leaves maintained at 40 to $50^{\circ} \mathrm{C}$ 
with 12 to $20 \%$ RH. Spores on leaves maintained at $25^{\circ} \mathrm{C}$ with $34 \% \mathrm{RH}$ survived for only $15 \mathrm{~h}$. Kochman (28), studying the effect of temperature on the development of $P$. pachyrhizi, concluded that certain temperatures are more conducive to rust development and survival than others; for example, a 17 to $27^{\circ} \mathrm{C}$ regime provided the best conditions for rust development while germination was significantly reduced when urediniospores were exposed to temis one of many methods used to eradicate pathogens. Our study supported the heat treatment at $50^{\circ} \mathrm{C}$ for $12 \mathrm{~h}$ for killing urediniospores on infected soybean leaf samples; however, the same results were achieved when urediniospores were exposed for $12 \mathrm{~h}$ at $40^{\circ} \mathrm{C}$ with $15 \% \mathrm{RH}$ or $20 \mathrm{~h}$ at $30^{\circ} \mathrm{C}$ with $25 \% \mathrm{RH}$. A previous study reported that urediniospores maintained at room temperature $\left(23\right.$ to $24^{\circ} \mathrm{C}$ with 55 to $60 \% \mathrm{RH}$ ) survived for 18 days when maintained on infected leaves and up to 30 days for spores dehydrated for $12 \mathrm{~h}$ before being placed in cryovials (13). This indicates that survival of urediniospores is highly affected by environmental conditions (29).

Urediniospore germination of $P$. pachyrhizi was reduced when exposed to low $\mathrm{RH}$ compared with those exposed to higher RH. This has also been reported for Gibberella zeae (6) and contrasts with other reports that spore longevity is increased at lower RH $(47,51)$. When urediniospores were exposed to $92.5 \% \mathrm{RH}$, germination was relatively high and decreased rapidly after 10 days. It was reported that at high RH (91 to $100 \%)$, spores contain a greater proportion of water in the free state and less food reserves available in the protoperatures of 28.5 to $42.5^{\circ} \mathrm{C}$. Heat treatment

plasm (33), resulting in a rapid loss in viability (5).

Storage in liquid nitrogen has been reported to be an effective way to preserve many, if not most, organisms $(12,36)$. The reversion of dormancy induced by liquid nitrogen storage on $P$. pachyrhizi urediniospores can be accomplished by subjecting them to a thermal shock at $40^{\circ} \mathrm{C}$ for $5 \mathrm{~min}$ followed by hydration for 12 to $16 \mathrm{~h}$ $(8,13)$. In our study, urediniospore hydration overnight (or for $12 \mathrm{~h}$ ) was the major factor for the dormancy reversion; thermal shock with hydration and no thermal shock with hydration treatments had consistently similar germination rates. A similar observation has previously been reported when studying dormancy reversion of $P$. pachyrhizi urediniospores stored at $-80^{\circ} \mathrm{C}(13)$.

\section{ACKNOWLEDGMENTS}

This research was supported in part by the United Soybean Board.

\section{LITERATURE CITED}

1. Achar, P. N. 1998. Effects of temperature on germination of Peronospora parasitica conidia and infection of Brassica oleracea. J. Phytopathol. 146:137-141.

2. Akinsanmi, O. A., Ladipo, J. L., and Oyekan, P. O. 2001. First report of soybean rust (Phakopsora pachyrhizi) in Nigeria. Plant Dis. 85:97.

3. Asnaghi, C., D'Hont, A., Glaszmann, J. C., and Rott, P. 2001. Resistance of sugarcane cultivar R 570 to Puccinia melanocephala isolates from different geographic locations. Plant Dis. 85:282-286.

4. Atif, A. H., and Wilcoxson, R. D. 1975. Responses of detached tissues of adult wheat plants to Puccinia graminis tritici. Phytopathology 65:318-321.

5. Bernd, R. B., Bean, G. A., Conway, W. S., and Moline, H. E. 1987. Influence of temperature and relative humidity on germinability of Mucor piriformis spores. J. Phytopathol. 118:3-8.

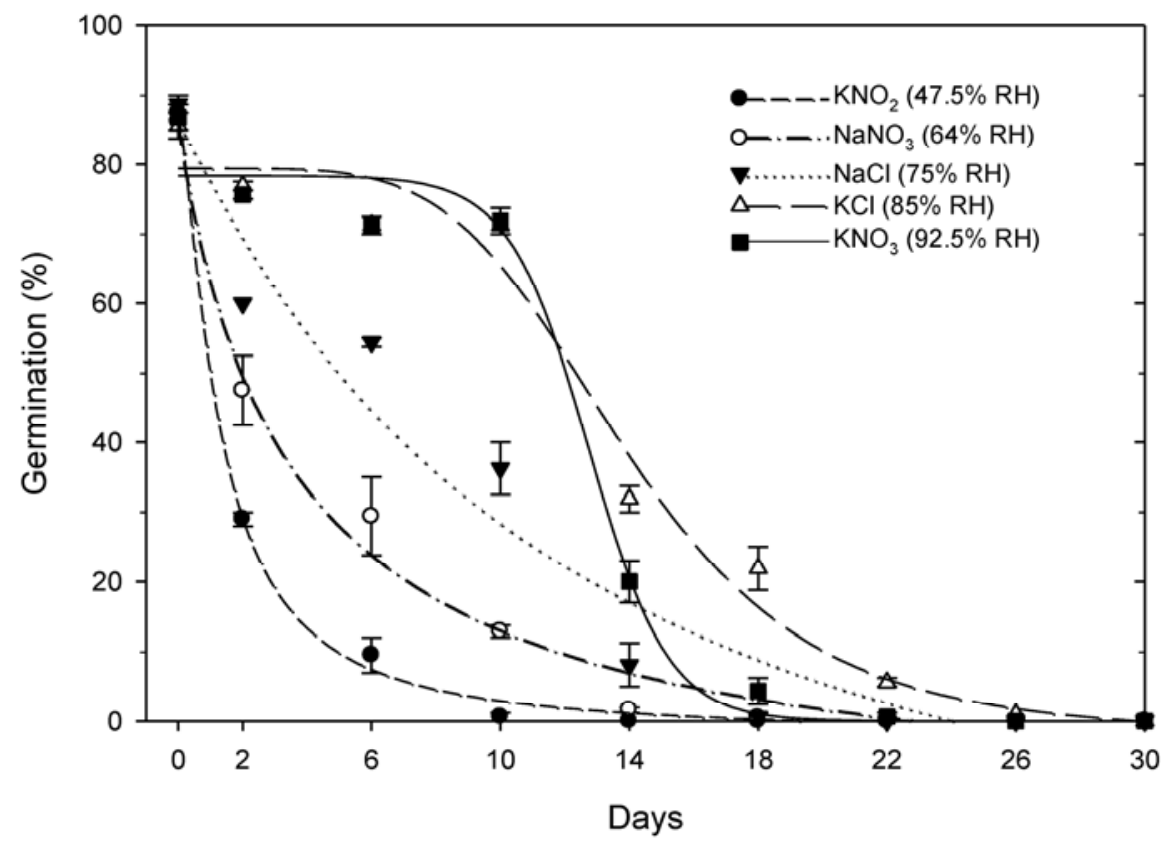

Fig. 7. Germination rates of Phakopsora pachyrhizi urediniospores exposed to different relative humidities. Vertical bars represent standard errors of the mean.
6. Beyer, M., and Verreet, J.-A. 2005. Germination of Gibberella zeae ascospores as affected by age of spores after discharge and environmental factors. Eur. J. Plant Pathol. 111:381-389.

7. Bonde, M. R., Berner, D. K., Nester, S. E., and Frederick, R. D. 2007. Effects of temperature on urediniospore germination, germ tube growth, and initiation of infection in soybean by Phakopsora isolates. Phytopathology 97:997-1003.

8. Bromfield, K. R. 1964. Cold-induced dormancy and its reversal in uredospores of Puccinia graminis var. tritici. Phytopathology 54:68-74.

9. Bromfield, K. R. 1984. Soybean Rust Monograph, No. 11. American Phytopathological Society, St. Paul, MN.

10. Burdon, J. J., and Marshall, D. R. 1981. Evaluation of Australian native species of Glycine for resistance to soybean rust. Plant Dis. 65:44-45.

11. Butler, D. R., Wadia, K. D. R., and Jadhav, D. R. 1994. Effects of leaf wetness and temperature on late leaf-spot infection of groundnut. Plant Pathol. 43:112-120.

12. Cunningham, J. L. 1973. Preservation of rust fungi in liquid nitrogen. Cryobiology 10:361363.

13. Furtado, G. Q., Alves, S., Czermainski, A., and Massola, N. 2007. Preservation of Phakopsora pachyrhizi uredospores. J. Phytopathol. 156:62-64.

14. Gregory, P. H. 1973. The Microbiology of the Atmosphere. Wiley, New York.

15. Gupta, V. P., Tewari, S. K., and Datta, R. K. 1994. Surface ultrastructure of the uredinial stage of Cerotelium fici and its infection process on mulberry. Mycopathologia 128:99-104.

16. Hartman, G. L., Wang, T. C., and Tschanz, A. T. 1991. Soybean rust development and the quantitative relationship between rust severity and soybean yield. Plant Dis. 75:596-600.

17. Hennings, V. P. 1903. A few new Japanese Uredinaceae. Hedwigia 42:S107-108.

18. Herath, I. H. M. H. B., Stoddard, F. L., and Marshall, D. R. 2001. Evaluating faba beans for rust resistance using detached leaves. Euphytica 117:47-57.

19. Hollis, C. A., Schmidt, R. A., and Kimbrough, J. W. 1972. Axenic culture of Cronartium fusiforme. Phytopathology 62:1417-1419.

20. Hong, T. D., Ellis, R. H., Gunn, J., and Moore, D. 2002. Relative humidity, temperature, and the equilibrium moisture content of conidia of Beauveria bassiana (Balsamo) Vuillemin: a quantitative approach. J. Stored Prod. Res. 38:33-41.

21. Hooker, A. L., and Yarwood, C. E. 1966. Culture of Puccinia sorghi on detached leaves of corn and Oxalis corniculata. Phytopathology 56:536-539.

22. Isard, S. A., Dufault, N. S., Miles, M. R., Hartman, G. L., Russo, J. M., De Wolf, E. D., and Morel, W. 2006. The effect of solar irradiance on the mortality of Phakopsora pachyrhizi urediniospores. Plant Dis. 90:941945.

23. Isard, S. A., Gage, S. H., Comtois, P., and Russo, J. M. 2005. Principles of the atmospheric pathway for invasive species applied to soybean rust. BioScience 55:851-861.

24. Jackson, E. W., Obert, D. E., Chong, J., Avant, J. B., and Bonman, J. M. 2008. Detached-leaf method for propagating Puccinia coronata and assessing crown rust resistance in oat. Plant Dis. 92:1400-1406.

25. Kawuki, R. S., Adipala, E., Lamo, J., and Tukamuhabwa, P. 2003. Responding to the soybean rust epidemic in sub-Saharan Africa: a review. Afr. Crop Sci. 11:301-318.

26. Koch, E., Ebrahim-Nesbat, F., and Hoppe, H. H. 1983. Light and electron microscopic studies on the development of soybean rust (Pha- 
kopsora pachyrhizi Syd.) in susceptible soybean leaves. Phytopathol. Z. 106:302-320.

27. Koch, E., and Hoppe, H. H. 1988. Development of infection structures by the direct-penetrating soybean rust fungus (Phakopsora pachyrhizi Syd.) on artificial membranes. J. Phytopathol. 122:232-244.

28. Kochman, J. K. 1979. The effect of temperature on development of soybean rust (Phakopsora pachyrhizi). Aust. J. Agric. Res. 30:273-277.

29. Kramer, C. L., and Pady, S. M. 1968. Viability of airborne spores. Mycologia 60:448-449.

30. Kuhl, J. L., Maclean, D. J., Scott, K. J., and Williams, P. G. 1971. The axenic culture of Puccinia species from uredospores: experiments on nutrition and variation. Can. J. Bot. 49:201-209.

31. Levy, C. 2005. Epidemiology and chemical control of soybean rust in Southern Africa. Plant Dis. 89:669-774.

32. Maddison, A. C., and Manners. J. G. 1972. Sunlight and viability of cereal rust uredospores. Trans. Br. Mycol. Soc. 59:429-443.

33. Merek, E. L., and Fergus, C. L. 1954. The effect of temperature and relative humidity on the longevity of spores of the oak wilt fungus. Phytopathology 44:61-64.

34. Miles, M. R., Levy, C., Morel, W., Mueller, T., Steinlage, T., van Rij, N., Frederick, R. D., and Hartman, G. L. 2007. International fungicide efficacy trials for the management of soybean rust. Plant Dis. 91:1450-1458.

35. Mueller, T. A., Miles, M. R., Morel, W., Marios, J. J., Wright, D. L., Kemerait, R. C., Levy, C., and Hartman, G. L. 2009. Effect of fungicide and timing of application on soybean rust severity and yield. Plant Dis. 93:243-248.

36. Nakasone, K. K., Peterson, S. W., and Jong, S. C. 2004. Preservation and distribution of fungal cultures. Pages 37-47 in: Biodiversity of Fungi. G. M. Meller, G. F. Bills, and M. S. Foster, eds. Elsevier Academic Press, MA

37. Ono, Y., Buritica, P., and Hennen, J. F. 1992. Delimitation of Phakopsora, Physopella and Cerotelium and their species on Leguminosae. Mycol. Res. 96:825-850.

38. Park, S., Chen, Z.-Y., Chanda, A. K.,
Schneider, R. W., and Hollier, C. A. 2008. Viability of Phakopsora pachyrhizi urediniospores under simulated southern Louisiana winter temperature conditions. Plant Dis. 92:14561462.

39. Paul, C., and Hartman, G. L. 2009. Sources of soybean rust resistance challenged with singlespored isolates of Phakopsora pachyrhizi collected from the USA. Crop Sci. 49:17811785.

40. Pei, M. H., and Gibbs, J. N. 1992. Axenic culture of Peridermium pini from single aeciospores. Plant Pathol. 41:91-94.

41. Punithalingam, E. 1971. Basidiomycetes: Heterobasidiomycetidae. Pages 193-218 in: Methods in Microbiology. C. Booth, ed. Academic Press, London.

42. Rossi, R. L. 2003. First report of Phakopsora pachyrhizi, the causal agent of soybean rust in the province of Misiones, Argentina. Plant Dis. 87:102.

43. Rotem, J., Wooding, B., and Aylor, D. E. 1985. The role of solar radiation, especially ultraviolet, in the mortality of fungal spores. Phytopathology 75:510-514.

44. Šafránková, I. 2008. New records of Chrysomyxa rhododendri on Rhododendron species. Plant Prot. Sci. 44:97-100.

45. Schneider, R. W., Hollier, C. A., Whitam, H. K., Palm, M. E., McKemy, J. M., Hernandez, J. R., Levy, L., and DeVries-Paterson, R. 2005. First report of soybean rust caused by Phakopsora pachyrhizi in the continental United States. Plant Dis. 89:774.

46. Slaminko, T. L., Miles, M. R., Frederick, R. D., Bonde, M. R., and Hartman, G. L. 2008. New legume hosts of Phakopsora pachyrhizi based on greenhouse evaluations. Plant Dis. 92:767-771.

47. Smilanick, J. L., and Mansour, M. F. 2007. Influence of temperature and humidity on survival of Penicillium digitatum and Geotrichum citri-aurantii. Plant Dis. 91:990-996.

48. Smith, D., and Onions, A. H. S. 1994. The Preservation and Maintenance of Living Fungi. CAB International, Wallingford, UK.

49. Sozzi, D., and Staub, T. 1987. Accuracy of methods to monitor sensitivity of Phytoph- thora infestans to phenylamide fungicides. Plant Dis. 71:422-425.

50. Tan, Y. 1994. Epidemiology of soybean rust in China. Pages 50-58 in: The Advance of Soybean Rust Research. Proc. Meeting Held in 1992. Hubei Science and Technology Publishing House, Wuhan, Peoples Republic of China.

51. Teitell, L. 1958. Effects of relative humidity on viability of conidia of Aspergilli. Am. J. Bot. 45:748-753.

52. Tunali, B., Yildirim, A., Aime, M. C., Hernández, J., and Berner, D. 2005. First Report of the rust fungus Coleosporium tussilaginis on Tussilago farfara in Turkey. Plant Dis. 89:1131.

53. Twizeyimana, M., Ojiambo, P. S., Ikotun, T., Paul, C., Hartman, G. L., and Bandyopadhyay, R. 2007. Comparison of field, greenhouse, and detached-leaf evaluations of soybean germplasm for resistance to Phakopsora pachyrhizi. Plant Dis. 91:1161-1169.

54. Twizeyimana, M., Ojiambo, P. S., Sonder, K., Ikotun, T., Hartman, G. L., and Bandyopadhyay, R. 2009. Pathogenic variation of Phakopsora pachyrhizi infecting soybean in Nigeria. Phytopathology 99:353-361.

55. Twizeyimana, M., Ojiambo, P. S., Tenkouano, A., Ikotun, T., and Bandyopadhyay, R. 2007. Rapid screening of Musa species for resistance to black leaf streak using in vitro plantlets in tubes and detached leaves. Plant Dis. 91:308 314.

56. Winston, P. W., and Bates, D. H. 1960. Saturated solutions for the control of humidity in biological research. Ecology 41:232-237.

57. Xie, G. L., and Mew, T. W. 1998. A leaf inoculation method for detection of Xanthomonas oryzae pv. oryzicola from rice seed. Plant Dis. 82:1007-1011.

58. Yamaoka, Y. 2002. Artificial culture of rust fungi. Yet-to-be-Cult. Microbiol. Cult. Coll. 14-17.

59. Yorinori, J. T., Paiva, W. M., Frederick, R. D., Costamilan, L. M., Bertagnolli, P. F., Hartman, G. L., Godoy, C. V., and Nunes, J., Jr. 2005 Epidemics of soybean rust (Phakopsora pachyrhizi) in Brazil and Paraguay from 20012003. Plant Dis. 89:675-677. 